\title{
Osteoporotic fracture rates in chronic hemodialysis and effect of heparin exposure: a retrospective cohort study
}

\author{
Hind Harrak ${ }^{1}$, Emilie René ${ }^{1}$, Noor Alsalemi ${ }^{1}$, Naoual Elftouh ${ }^{1}$ and Jean-Philippe Lafrance ${ }^{1,2,3^{*}}$ [D
}

\begin{abstract}
Background: Patients receiving chronic hemodialysis treatments are at a higher risk of fracture compared to the general population. While the use of heparin during dialysis is crucial to avoid thrombosis of the extracorporeal circuit, the association of unfractionated heparin (UFH) and the risk of osteoporotic fracture has been shown for many years. However, this association was not as clear for low-molecular-weight heparin $(\mathrm{LMWH})$ and the few collected data originated from studies among pregnant women. Our aim was to measure osteoporotic fracture rate among hemodialysis patients and to evaluate the association of LMWH compared to UFH in hemodialysis.

Methods: A retrospective cohort study was conducted on data extracted from the RAMQ and Med-Echo databases from January 2007 to March 2013 with patients chronically hemodialyzed in 21 participating centers. Incidence rates for each fracture sites were measured per 1000 patient-year ( $p-y)$ and their 95\% confidence intervals (CI). Osteoporotic fracture risk for a first event with LMWH compared to UFH was estimated using a cox proportional hazard model using demographics, comorbidities and drug use as covariates.
\end{abstract}

Results: 4796 patients undergoing chronic hemodialysis were identified. The incidence rate for all fracture sites was $22.7 / 1000$ p-y (95\% Cl: 19.6-26.1) and 12.8/1000 p-y (95\% Cl: 10.5-15.4) for hip and femur fractures. We found a similar risk of osteoporotic fracture for LMWH compared to UFH (adjusted HR=1.01; 95\%Cl: 0.72-1.42). Age and malignancy increased the risk of fracture while cerebrovascular disease decreased the risk of fracture.

Conclusions: Compared to UFH, LMWH did not change the risk of osteoporotic fracture when used for the extracorporeal circuit anticoagulation in chronic hemodialysis.

Keywords: Heparin, low molecular weight, Unfractionated heparin, Osteoporotic fracture, Kidney failure, chronic, Pharmacoepidemiology

\footnotetext{
* Correspondence: jean-philippe.lafrance@umontreal.ca

'Centre de recherche Hôpital Maisonneuve-Rosemont, Montréal, Canada

${ }^{2}$ Service de néphrologie, Hôpital Maisonneuve-Rosemont, 5415, boul. de l'Assomption, Montréal, Québec H1T 2M4, Canada

Full list of author information is available at the end of the article
}

(C) The Author(s). 2020 Open Access This article is licensed under a Creative Commons Attribution 4.0 International License, which permits use, sharing, adaptation, distribution and reproduction in any medium or format, as long as you give appropriate credit to the original author(s) and the source, provide a link to the Creative Commons licence, and indicate if changes were made. The images or other third party material in this article are included in the article's Creative Commons licence, unless indicated otherwise in a credit line to the material. If material is not included in the article's Creative Commons licence and your intended use is not permitted by statutory regulation or exceeds the permitted use, you will need to obtain permission directly from the copyright holder. To view a copy of this licence, visit http://creativecommons.org/licenses/by/4.0/ The Creative Commons Public Domain Dedication waiver (http://creativecommons.org/publicdomain/zero/1.0/) applies to the data made available in this article, unless otherwise stated in a credit line to the data. 


\section{Background}

Hospitalization and mortality following a bone fracture are significantly higher among hemodialysis patients compared to the overall population [1]. Not only hemodialysis patients have worse outcomes after a fracture, they are also at a higher risk of bone disease and fracture [2-6]. Bone structure and function in these patients is altered by mineral and endocrine disorders [7]. Heparin plays a central role in preventing thrombosis of the extracorporeal circuit in hemodialysis. However, it was reported in animal models and human studies that heparin can induce osteoporosis [8-17]. The exact mechanism is still under investigation, but few hypotheses have been expressed. One possible reason for heparin-induced osteoporosis would be that heparin decreases the bone density by decreasing the number of osteoblasts and increasing the number of osteoclasts [18]. Another explored option was the interaction between heparin and the system composed of osteoprotegerin (OPG), the receptor activator of nuclear factor $\mathrm{kB}$ (RANK), and the receptor activator of nuclear factor $\mathrm{kB}$ ligand (RANKL), which is essential in bone remodeling [19-25]. It is still unclear if the induction of osteoporosis varied between unfractionated heparin (UFH) and lowmolecular-weight heparin (LMWH) and, furthermore, if the use of one form of heparin instead of the other changed the risk of fracture. Since the fracture risk is high among chronic hemodialysis patients and that they are usually chronically exposed to a therapeutic dose of heparin three times weekly during their hemodialysis treatment, a small relative reduction in the fracture risk may translate in the prevention of substantial number of fractures.

The aims of our study were 1) to evaluate fracture rates in a cohort of chronic hemodialysis patients; and 2) to measure the association between the type of heparin (LMWH compared to UFH) and the risk of osteoporotic fractures.

\section{Methods}

\section{Study population and data sources}

We used a retrospective cohort study to measure osteoporotic fracture rates and to evaluate the association of osteoporotic fracture risk and exposure to LMWH compared to UFH among prevalent and incident chronic hemodialysis patients. Data were obtained from the Régie de l'assurance maladie du Québec (RAMQ), a provincial health insurance plan of the Province of Québec, Canada, provided to all residents. This single-payer plan covers medical and hospital services. This administrative database provided all medical visits, diagnostic codes (using International Classification of Diseases - ICD), medical procedures during in- and outpatient encounters, and hospital discharge summaries (Med-Echo). The
Med-Echo database holds details on hospital stay, including the date of admission and discharge, primary and secondary diagnoses, and the procedures performed. The provincial drug plan covers all individuals, including workers with no private insurance, aged 65 years and older, and individuals receiving welfare. RAMQ drug plan does not report exposure to heparin during hemodialysis and therefore this information was collected at each of the 21 participating hemodialysis units in the province of Quebec. The list of participating centers is provided in the supplementary appendix.

\section{Study cohort}

Our cohort is formed of both prevalent and incident adult patients on maintenance hemodialysis between January 1st, 2007 and March 31st, 2013 identified in the RAMQ database. Inclusion criteria are defined as follow: patients could not have a prior kidney transplant and should have at least 90 days of follow-up after hemodialysis initiation. The cohort entry date corresponds to the first hemodialysis date respecting the inclusion criteria. However, follow-up began only when a patient was exposed to one form of heparin for at least 3 months after cohort entry (index date). End of followup was defined as the date of kidney transplant, switch to peritoneal dialysis or home dialysis, switched heparin form or with unknown heparin exposure status, end of study or death, whichever occurred first.

\section{Exposure definition}

Anticoagulant administration is part of the hemodialysis session and is performed in hospital. Therefore, the type of heparin received by the patient is not available in the RAMQ drug plan database. Each patient was assigned to the heparin regimen that corresponded to the unit's common protocol. We collected the type of heparin used (tinzaparin, dalteparin, enoxaparin, nadroparin, or UFH) for each center between January 1st, 2007 and March 31st, 2013. Protocol changes were documented allowing for switch between heparin regimen through the study period. Multiple changes of heparin could be reported for each hemodialysis center, however transition periods from one heparin to another were removed from the analysis. Patients' exposure status was assigned based on the center where they were receiving hemodialysis.

\section{Outcome definition}

We used a validated algorithm published by Jean et al. [26] to identify incident osteoporotic fracture events during patients' follow-up time, using a combination of physician claims and ICD-10 codes. Briefly, the algorithm identifies incident fractures through two ways: 1) a physician claim that is specific to fracture treatment: 
closed reduction, open reduction or immobilization; 2) a billing code for a medical visit with an osteoporotic surgeon combined with some specific ICD-10 diagnostic codes and another claim for a principal visit (emergency physician or general practitioner) with some specific ICD-10 diagnostic codes. The list of billing claim codes and ICD-9/ICD-10 codes provided in supplementary Tables S1 and S2. A total of 12 osteoporotic fracture sites and one unspecified osteoporotic fracture site categories were evaluated in our cohort. Only the first fracture was considered for each patient.

\section{Covariates}

The following covariates were evaluated at the index date: age, gender, follow-up time, vintage time (time undergoing chronic hemodialysis for prevalent patients), hospitalization in prior year, comorbidities in the 2 years prior to index date, and drug use in the 6 months prior to the index date (see Table 1 for more details).

\section{Statistical analysis}

Baseline data were described as mean and standard deviation (SD) or median and interquartile range (IQR) a where appropriate. Comorbidities are presented as frequency and proportions (\%).

Incidence rates for outcomes were calculated by dividing the number of events (total osteoporotic fractures or osteoporotic fractures by site) by the total patient-years (p-y) of follow-up. 95\% confidence intervals (CI) for rates were calculated using a Poisson distribution (inversed gamma formula).

The hazard ratio (HR) for the first fracture per patient was estimated using a cox proportional hazard model. It was adjusted for all the comorbidities presented in Table 1. All analyses were done using SAS 9.4 (Cary, North Carolina).

\section{Sensitivity analysis}

LMWH differ from one another and their effect on bone metabolism could vary. We conducted the analyses using the same method but separating tinzaparin periods from dalteparin (UFH was kept as the reference group). Finally, we performed an additional analysis including either only incident patients or prevalent patients from our cohort.

\section{Ethical considerations}

This study was approved by the Government of Québec ethics committee (Commission d'accès à l'information) and all hospitals ethics committees. Informed consent was waived.

\section{Results}

A total of 4796 incident and prevalent patients on maintenance hemodialysis were identified between January 1st,
2007 and March 31st, 2013. Median follow-up time was 1.95 years (IQR: $0.87-3.68$ ) for the total cohort, with incident patients representing $68.9 \%$ of the patients. The mean age after 3 months of exposure was $67.0 \pm 14.0$ years and women represented 39.7\%. LMWH patients represented $30 \%$ of the cohort. When comparing the proportion of patients receiving LMWH and UFH by year of cohort entry, $22 \%$ of patients were receiving LMWH between 2007 and 2009. In 2010, $35 \%$ of the patients were receiving LMWH and 50\% of patients entering in the cohort in 2011-2012 were receiving LMWH. Patients' characteristics were overall similar (Table 1). However, patients in the LMWH group were older, were more incident than prevalent, had more hypertension, less history of parathyroidectomy and slightly different prescription drugs.

Table 1 Characteristics of patients receiving LMWH compared to UFH in hemodialysis

\begin{tabular}{llll}
\hline Covariates & LMWH & UFH & $p$ value \\
& $n=1426(\%)$ & $n=3370(\%)$ & \\
\hline Age $^{\text {a }}$ (years) \pm SD & $67.88 \pm 13.7$ & $66.57 \pm 14.2$ & 0.003 \\
Sex (Female) & $589(41.3)$ & $1316(39.1)$ & 0.14 \\
Hemodialysis incidence & $1090(76.4)$ & $2215(65.7)$ & $<0.0001$ \\
Hospitalization in prior year & $1117(78.3)$ & $2678(79.5)$ & 0.38 \\
Comorbidities & & & \\
Cardiovascular disease & $757(53.1)$ & $1836(54.5)$ & 0.38 \\
Cerebrovascular disease & $121(8.5)$ & $315(9.4)$ & 0.34 \\
Chronic pulmonary disease & $324(22.7)$ & $711(21.1)$ & 0.21 \\
Chronic liver disease & $72(5.1)$ & $213(6.3)$ & 0.09 \\
Congestive heart failure & $473(33.2)$ & $1051(31.2)$ & 0.18 \\
Diabetes & $796(55.8)$ & $1823(54.1)$ & 0.27 \\
Hyperlipidemia & $876(61.4)$ & $2132(63.3)$ & 0.23 \\
Hypertension & $1169(82.0)$ & $2614(77.6)$ & 0.001 \\
Malignancy & $289(20.3)$ & $679(20.2)$ & 0.93 \\
Peripheral vascular disease & $407(28.5)$ & $992(29.4)$ & 0.53 \\
Rheumatoid arthritis & $22(1.5)$ & $66(2.0)$ & 0.33 \\
Osteoporosis & $92(6.5)$ & $205(6.1)$ & 0.63 \\
Parathyroidectomy & $0(0.0)$ & $10(0.3)$ & 0.04 \\
Prior fracture & $34(2.4)$ & $100(3.0)$ & 0.26 \\
Drug use & & & \\
NSAlDs & $743(52.1)$ & $1763(52.3)$ & 0.89 \\
Steroids & $212(14.9)$ & $565(16.8)$ & 0.10 \\
Calcium & $872(61.2)$ & $2121(62.9)$ & 0.24 \\
Vitamin D & $801(56.2)$ & $1750(51.9)$ & 0.01 \\
Phosphorus chelating agents & $914(64.1)$ & $2249(66.7)$ & 0.08 \\
Cinacalcet & $14(1.0)$ & $18(0.5)$ & 0.08 \\
\hline
\end{tabular}

${ }^{\mathrm{a} A t}$ index date

${ }^{\mathrm{b}}$ At index date in the two years prior

${ }^{C} A t$ index date in the six months prior

Abbreviations: SD Standard deviation, NSAID Non-steroidal anti-inflammation drugs, LMWH Low Molecular Weight heparin, UFH Unfractionated heparin 
The incidence rate for a first fracture, when all sites were combined, was 22.7 /1000 p-y (95\% CI: 19.6-26.1) with hip and femur fractures being the most common with a rate of 12.8 /1000 p-y (95\% CI: 10.5-15.4). Rates of first fracture for all included sites are provided in Table 2. Fracture rates were similar for both LMWH and UFH groups.

Using a multivariable model, the fracture risk was also similar for LMWH compared to UFH $(\mathrm{HR}=1.01$; 95\%CI: 0.72-1.42). However, older age $(\mathrm{HR}=1.02$; $95 \%$ CI: $1.01-1.04)$ and malignancy $(\mathrm{HR}=1.50 ; 95 \% \mathrm{CI}$ : 1.07-2.10) were associated with a higher risk of fracture. Cerebrovascular disease was associated with a lower risk of fracture (HR $=0.46$; 95\% CI: 0.24-0.89). Detailed results are presented in Table 3.

\section{Sensitivity analysis}

When comparing single LMWH agent to UFH, neither tinzaparin (HR $=0.94 ; 95 \% \mathrm{CI}: 0.66-1.34)$ nor dalteparin $(\mathrm{HR}=2.35 ; 95 \% \mathrm{CI}: 0.91-6.03)$ were associated with a different fracture risk than UFH. In the second sensitivity analysis where only incident patients were included, the fracture risk remained similar when comparing LMWH to UFH ( $\mathrm{HR}=0.89$; 95\% CI: $0.58-1.38)$. Our final sensitivity analysis including only prevalent patients showed no association between the type of heparin and fracture risk $(\mathrm{HR}=1.07$; 95\% CI: $0.60-1.91)$.

\section{Discussion}

In this retrospective cohort, we evaluated the incidence rate of osteoporotic fractures among chronic hemodialysis patients. We also estimated the risk of fracture associated with $\mathrm{LMWH}$ and differentiating between tinzaparin and dalteparin. Regardless of the type of LMWH administered, there was no difference in fracture risk compared to UFH.

Fracture rates from our cohort are consistent with rates presented by Jadoul et al. from the second phase of the Dialysis Outcomes and Practice Patterns Study (DOPPS II) which includes data from 12 countries [4]. The authors reported a total incidence rate for any fracture of 25.6 events /1000 p-y (95\%CI: 24.4-27.0) and 8.9 events /1000 p-y (95\% CI: 8.4-9.4) for hip fracture. Both our results and results from DOPPS II show higher fracture incidence rates compared to the general population that showed hip fracture rates varying between 1 and 5 events /1000 p-y [27].

Our results show no fracture risk difference with LMWH compared to UFH among chronic hemodialysis patients. Case reports and studies reporting an association between UFH and osteoporosis and osteoporotic fractures have been discussed for more than 50 years, [8] but most data are from pregnant women using long term heparin to prevent pregnancy loss [28, 29]. Even in this population, the association of LMWH and osteoporosis remains controversial $[30,31]$. The proposed mechanism to explain the reduction of osteoporosis associated with LMWH is the following: While both LMWH and UFH decrease osteoblast count, UFH would trigger a higher increase of osteoclast surface and a greater loss of calcium than LMWH $[18,32]$.

In our cohort, age was associated with an increased risk of fracture. In a recent study by Wagner et al. [33] using data from the US Renal Data System (USRDS), reported that white patients aged 65 years or more

Table 2 Incidence rates for the first fracture by site (per 1000 person-year)

\begin{tabular}{|c|c|c|c|c|}
\hline \multirow[t]{2}{*}{ Site } & \multirow{2}{*}{$\begin{array}{l}\text { All } \\
\text { Rate }(95 \% \mathrm{Cl})\end{array}$} & \multirow{2}{*}{$\begin{array}{l}\text { LMWH } \\
\text { Rate }(95 \% \mathrm{Cl})\end{array}$} & \multirow{2}{*}{$\begin{array}{l}\text { UFH } \\
\text { Rate }(95 \% \mathrm{Cl})\end{array}$} & \multirow[t]{2}{*}{$\overline{p \text { value }}$} \\
\hline & & & & \\
\hline All Sites & $22.7(19.6-26.1)$ & $22.5(16.5-29.9)$ & $22.7(19.2-26.7)$ & 0.95 \\
\hline Ankle & $1.5(0.8-2.6)$ & $1.4(0.3-4.1)$ & $1.5(0.7-2.8)$ & 0.89 \\
\hline Hip and Femur & $12.8(10.5-15.4)$ & $14.7(10.0-20.8)$ & $12.1(9.6-15.1)$ & 0.39 \\
\hline Foot & $0.5(0.1-1.2)$ & $n / a$ & $0.6(0.2-1.6)$ & \\
\hline Forearm fracture & $1.5(0.8-2.6)$ & $1.4(0.3-4.1)$ & $1.5(0.7-2.8)$ & 0.8864 \\
\hline Humerus & $0.8(0.3-1.7)$ & $1.4(0.3-4.1)$ & $0.6(0.2-1.6)$ & 0.3630 \\
\hline Knee & $0.7(0.3-1.5)$ & $0.9(0.1-3.4)$ & $0.6(0.2-1.6)$ & 0.6603 \\
\hline Pelvis & $0.8(0.3-1.7)$ & $0.5(0.0-2.6)$ & $0.9(0.3-2.0)$ & 0.4486 \\
\hline Shoulder fracture & $0.7(0.3-1.5)$ & $0.5(0.0-2.6)$ & $0.8(0.2-1.8)$ & 0.6033 \\
\hline Spine & $0.8(0.3-1.7)$ & $n / a$ & $1.1(0.4-2.2)$ & \\
\hline Tibia & $0.5(0.1-1.2)$ & $n / a$ & $0.6(0.2-1.6)$ & \\
\hline Upper limb & $n / a$ & $n / a$ & $n / a$ & \\
\hline Wrist & $1.3(0.6-2.3)$ & $1.4(0.3-4.1)$ & $1.2(0.5-2.4)$ & 0.85 \\
\hline Unspecified & $0.5(0.1-1.2)$ & $n / a$ & $0.6(0.2-1.6)$ & \\
\hline
\end{tabular}

Abbreviations: LMWH Low Molecular Weight heparin, UFH Unfractionated heparin, CI Confidence interval 
Table 3 Estimated risk of osteoporotic fracture associated with LMWH in hemodialysis

\begin{tabular}{|c|c|c|}
\hline Variables & $\begin{array}{l}\text { Unadjusted HR } \\
(95 \% \mathrm{Cl})\end{array}$ & $\begin{array}{l}\text { Adjusted HR } \\
(95 \% \mathrm{Cl})\end{array}$ \\
\hline \multicolumn{3}{|l|}{ Baseline } \\
\hline Heparin Exposure LMWH (vs UFH) & $1.00(0.72-1.39)$ & $1.01(0.72-1.42)$ \\
\hline Age (per year) & $1.02(1.01-1.04)$ & $1.02(1.01-1.04)^{* *}$ \\
\hline Male (vs female) & $1.24(0.94-1.65)$ & $1.21(0.90-1.62)$ \\
\hline Incident patients (vs prevalent) & $0.89(0.67-1.20)$ & $0.84(0.61-1.16)$ \\
\hline Hospitalization in prior year & $1.11(0.79-1.55)$ & $1.14(0.77-1.70)$ \\
\hline \multicolumn{3}{|l|}{ Comorbidities } \\
\hline Cardiovascular disease & $1.14(0.85-1.51)$ & $0.91(0.65-1.28)$ \\
\hline Cerebrovascular disease & $0.58(0.30-1.09)$ & $0.46(0.24-0.89)^{*}$ \\
\hline Chronic pulmonary disease & $1.30(0.93-1.82)$ & $1.20(0.84-1.71)$ \\
\hline Chronic liver disease & $1.10(0.60-2.02)$ & $1.25(0.67-2.31)$ \\
\hline Congestive heart failure & $1.34(1.00-1.81)$ & $1.24(0.88-1.75)$ \\
\hline Diabetes & $1.20(0.90-1.60)$ & $1.25(0.92-1.72)$ \\
\hline Hyperlipidemia & $1.22(0.90-1.66)$ & $1.16(0.82-1.65)$ \\
\hline Hypertension & $0.96(0.69-1.34)$ & $0.75(0.51-1.11)$ \\
\hline Malignancy & $1.53(1.10-2.12)$ & $1.50(1.07-2.10)^{*}$ \\
\hline Peripheral vascular disease & $1.29(0.95-1.75)$ & $1.29(0.92-1.81)$ \\
\hline Rheumatoid arthritis & $1.73(0.71-4.21)$ & $1.51(0.61-3.75)$ \\
\hline Osteoporosis & $1.48(0.87-2.51)$ & $1.20(0.69-2.09)$ \\
\hline Prior fracture & $1.57(0.77-3.18)$ & $1.33(0.64-2.76)$ \\
\hline \multicolumn{3}{|l|}{ Drug use 6 months prior } \\
\hline NSAID & $1.03(0.77-1.37)$ & $0.87(0.63-1.20)$ \\
\hline Steroids & $1.04(0.70-1.54)$ & $0.97(0.64-1.46)$ \\
\hline Calcium & $1.04(0.77-1.41)$ & $1.07(0.62-1.85)$ \\
\hline Vitamin D & $1.32(0.99-1.77)$ & $1.37(0.98-1.92)$ \\
\hline Phosphorus chelating agents & $0.96(0.70-1.30)$ & $0.71(0.41-1.26)$ \\
\hline Cinacalcet & $0.53(0.07-3.80)$ & $0.62(0.09-4.47)$ \\
\hline
\end{tabular}

Abbreviations: HR Hazard ratio, CI Confidence interval, NSAID Non-steroidal anti-inflammation drugs, LMWH Low Molecular Weight heparin, UFH Unfractionated heparin

$*$ : $p$ value $<0.05 ;{ }^{* *}: p$ value $<0.01$

undergoing hemodialysis had higher fracture rates compared to other age groups. We also observed an increased risk of fracture associated with malignancy. Multiple studies reported higher risk of fracture among patients with bone cancer, multiple myeloma, metastases to the bone and organs other than the bone, liver, gall bladder, pancreas, breast and other forms of cancer [34-38]. This increased risk could be explained by multiple factors like cancer treatments used [39-41], infiltration of cancer in bone tissue, a result of the systemic inflammation or parathyroid activity [42]. Our data showed a lower risk of fracture for patients with a history of cerebrovascular disease. However, previous studies found no association between cerebrovascular disease and risk of fracture, or reported an increased risk [43-46]. Why this result differs from previous studies remains unknown. A possible explanation could be that patients with cerebrovascular disease receive more intensive care with better control of fracture risk factors than patients without cerebrovascular disease [45]. Further studies on this topic are needed to clarify this association.

To our knowledge, this is the first study evaluating the risk of fracture associated with LMWH compared to UFH among chronic hemodialysis patients. Multiple studies reported on the risk of fracture in hemodialysis patients, or on heparin-induced osteoporosis, but none studied the association between type of heparin and the risk of fracture in the hemodialysis setting. Our study has several strengths. Outcomes were evaluated on large scale in this multicenter cohort study. The universal provincial health care insurance allowed including all eligible patients undergoing hemodialysis in participating units, limiting selection bias. Multiple covariates, 
including drug exposure, were collected from RAMQ and Med-echo and included in the analyses, and therefore minimizing confounding. Finally, we used a validated algorithm to identify osteoporotic fractures in the cohort. This algorithm was specifically designed for RAMQ data and showed an overall high sensitivity and positive predictive value.

Our study has some limitations. Exposure data was collected at the facility level and patients were attributed their exposure status based on the facility where they received hemodialysis treatment, introducing a potential misclassification bias. The proportion of patients who were not receiving the standard heparin regimen was not available. Since we excluded transition period, this proportion is thought to be small. Nevertheless, this bias should not be different between LMWH and UFH. Moreover, individual dosage was not available, limiting this adjustment in the analysis. Despite the validated algorithm to identify fracture events, some fractures may have been missed, especially for vertebral, sacral and coccyx fracture sites that had the lowest sensitivities. The algorithm was independent from the exposure status and should not influence the risk association. While we included numerous relevant covariables in our model, residual confounding is possible. If available, patients' biochemical profiles would have been valuable in our current study. Finally, only a small portion of patients were exposed to dalteparin, limiting the interpretation of the results for this specific agent.

\section{Conclusions}

In conclusion, our large retrospective cohort study showed that LMWH is not associated with a different risk of osteoporotic fracture than UFH among chronic hemodialysis patients when used for the extracorporeal circuit anticoagulation. Extracorporeal circuit anticoagulation during a hemodialysis session is mandatory, and ensuring that the increasing use of LMWH does not modify the risk of fractures is crucial.

\section{Supplementary information}

Supplementary information accompanies this paper at https://doi.org/10. 1186/s12882-020-01916-4.

Additional file 1: Table S1. Specific medical services billing codes for osteoporotic fractures by site. Table S2. Non-specific osteoporotic fracture billing codes and specific ICD-9/ICD-10 codes

\section{Abbreviations}

UFH: Unfractionated heparin; LMWH: Low-molecular-weight heparin; PY: Patient-year; Cl: Confidence interval; HR: Hazard ratio; DOPPS: Dialysis Outcomes and Practice Patterns Study; OPG: Osteoprotegerin; RANK: Receptor activator of nuclear factor kB; RANKL: Receptor activator of nuclear factor kB ligand; RAMQ: Régie de l'assurance maladie du Québec; ICD: International Classification of Diseases; SD: Standard deviation; IQR: Interquartile range; USRDS: US Renal Data System

\section{Acknowledgements}

We would like to thank all our collaborators in the participating centers who made exposure data collection, and this study, possible in their respective hemodialysis units. Dr. Pierre Cartier, Dr. Karine Tousignant, Dr. Carole Pichette, Dr. Gérard Désaulniers, Dr. Jean Proulx, Dr. Sacha Deserres, Dr. Paul Montambault, Dr. Jean-François Cailhier, Dr. George Soltys, Dr. Damien Bélisle, Dr. Marc Ghannoum, Dr. Jean-Philippe Rioux, Dr. Sylvain Brunet, Dr. Marie-Josée Dion, Dr. Paul Barré, Dr. Simon Desmeules.

\section{Authors' contributions}

Co-authors have all contributed to this manuscript and approve its submission. This manuscript is co-authored by HHL (conception and design, analysis and interpretation of data, and writing of manuscript), ER (interpretation of data, writing of manuscript and critical appraisal of article), NA (interpretation of data and critical appraisal), NE (analysis of data, and critical appraisal of article), and JPL (conception and design, analysis and interpretation of data, and writing of manuscript)

Funding

Not applicable.

\section{Availability of data and materials}

The data that support the findings of this study are available from RAMQ, MedEcho and from surveys conducted at participating centers but restrictions apply to the availability of these data, which were used under license for the current study, and so are not publicly available. Data cannot be shared due to a confidentiality agreement with the RAMQ and Ethics committees in each participating hospital.

Ethics approval and consent to participate

This study was approved by the Government of Québec ethics committee (Commission d'accès à l'information) and all hospitals ethics committees (Comité d'éthique de la recherché - CER). Informed consent was waived. List of participating centers.

Centre de services de Rivière Rouge.

Centre hospitalier affilié universitaire régional de Trois-Rivières.

Centre hospitalier de Granby.

Centre hospitalier Hôtel-Dieu-de-Sorel.

Centre hospitalier régional de Lanaudière.

Centre Hospitalier Universitaire de Québec (CHUQ).

Centre Hospitalier universitaire de Sherbrooke (CHUS).

CHUM St-LuC.

Hôpital Charles-LeMoyne.

Hôpital de Chicoutimi.

Hôpital de Rouyn-Noranda.

Hôpital de Verdun.

Hôpital du Sacré-cœur de Montréal.

Hôpital Honoré-Mercier.

Hôpital Maisonneuve-Rosemont.

Hôpital Pierre-LeGardeur.

Hôpital régional de Rimouski.

Hôpital régional de St-Jérôme.

Hôpital Royal Victoria du CUSM.

Hôpital Sainte-Croix.

Hôtel-Dieu de Lévis.

Consent for publication

Not applicable.

\section{Competing interests}

The authors declare that they have no competing interests.

\section{Author details}

${ }^{1}$ Centre de recherche Hôpital Maisonneuve-Rosemont, Montréal, Canada. ${ }^{2}$ Service de néphrologie, Hôpital Maisonneuve-Rosemont, 5415, boul. de I'Assomption, Montréal, Québec H1T 2M4, Canada. ${ }^{3}$ Département de pharmacologie et physiologie, Université de Montréal, Montréal, Canada. 
Received: 30 September 2019 Accepted: 28 June 2020

\section{Published online: 09 July 2020}

\section{References}

1. Tentori F, McCullough K, Kilpatrick RD, Bradbury BD, Robinson BM, Kerr PG, Pisoni RL. High rates of death and hospitalization follow bone fracture among hemodialysis patients. Kidney Int. 2014;85(1):166-73.

2. Wakasugi M, Kazama JJ, Taniguchi M, Wada A, Iseki K, Tsubakihara Y, Narita I. Increased risk of hip fracture among Japanese hemodialysis patients. J Bone Miner Metab. 2013;31(3):315-21.

3. Coco M, Rush $\mathrm{H}$. Increased incidence of hip fractures in dialysis patients with low serum parathyroid hormone. Am J Kidney Dis. 2000;36(6):1115-21.

4. Jadoul M, Albert JM, Akiba T, Akizawa T, Arab L, Bragg-Gresham JL, Mason N, Prutz KG, Young EW, Pisoni RL. Incidence and risk factors for hip or other bone fractures among hemodialysis patients in the Dialysis outcomes and practice patterns study. Kidney Int. 2006;70(7):1358-66.

5. Alem AM, Sherrard DJ, Gillen DL, Weiss NS, Beresford SA, Heckbert SR, Wong C, Stehman-Breen C. Increased risk of hip fracture among patients with end-stage renal disease. Kidney Int. 2000;58(1):396-9.

6. Ball AM, Gillen DL, Sherrard D, Weiss NS, Emerson SS, Seliger SL, Kestenbaum BR, Stehman-Breen C. Risk of hip fracture among dialysis and renal transplant recipients. JAMA. 2002;288(23):3014-8.

7. Eckardt KUKB. Kidney disease improving global outcomes (KDIGO): clinical practice guideline for the diagnosis, evaluation, prevention, and treatment of chronic kidney disease-mineral and bone disorder (CKD-MBD). Kidney Int Suppl. 2009;113:S1-130.

8. Griffith GC, Nichols G Jr, Asher JD, Flanagan B. Heparin osteoporosis. JAMA. 1965;193:91-4.

9. Jaffe MD, Willis PW 3rd. Multiple fractures associated with long-term sodium heparin therapy. JAMA. 1965;193:158-60.

10. Miller WE, DeWolfe VG. Osteoporosis resulting from heparin therapy. Report of a case. Cleve Clin Q. 1966;33(1):31-4.

11. Squires JW, Pinch LW. Heparin-induced spinal fractures. JAMA. 1979;241(22): 2417-8.

12. Rupp WM, McCarthy HB, Rohde TD, Blackshear PJ, Goldenberg FJ, Buchwald H. Risk of osteoporosis in patients treated with long-term intravenous heparin therapy. Curr Surg. 1982;39(6):419-22.

13. Murphy MS, John PR, Mayer AD, Buckels JA, Kelly DA. Heparin therapy and bone fractures. Lancet. 1992;340(8827):1098.

14. Dahlman TC. Osteoporotic fractures and the recurrence of thromboembolism during pregnancy and the puerperium in 184 women undergoing thromboprophylaxis with heparin. Am J Obstet Gynecol. 1993; 168(4):1265-70.

15. Barbour LA, Kick SD, Steiner JF, LoVerde ME, Heddleston LN, Lear JL, Baron $A E$, Barton PL. A prospective study of heparin-induced osteoporosis in pregnancy using bone densitometry. Am J Obstet Gynecol. 1994;170(3): 862-9.

16. Dahlman TC, Sjoberg HE, Ringertz H. Bone mineral density during long-term prophylaxis with heparin in pregnancy. Am J Obstet Gynecol. 1994;170(5 Pt 1):1315-20.

17. Monreal M, Lafoz E, Olive A, del Rio L, Vedia C. Comparison of subcutaneous unfractionated heparin with a low molecular weight heparin (Fragmin) in patients with venous thromboembolism and contraindications to coumarin. Thromb Haemost. 1994;71(1):7-11.

18. Muir JM, Andrew M, Hirsh J, Weitz JI, Young E, Deschamps P, Shaughnessy SG. Histomorphometric analysis of the effects of standard heparin on trabecular bone in vivo. Blood. 1996;88(4):1314-20.

19. Simonet WS, Lacey DL, Dunstan CR, Kelley M, Chang MS, Luthy R, Nguyen $H Q$, Wooden S, Bennett L, Boone T, et al. Osteoprotegerin: a novel secreted protein involved in the regulation of bone density. Cell. 1997;89(2):309-19.

20. Lacey DL, Timms E, Tan HL, Kelley MJ, Dunstan CR, Burgess T, Elliott R, Colombero A, Elliott G, Scully $\mathrm{S}$, et al. Osteoprotegerin ligand is a cytokine that regulates osteoclast differentiation and activation. Cell. 1998;93(2):165-76

21. Mizuno A, Amizuka N, Irie K, Murakami A, Fujise N, Kanno T, Sato Y, Nakagawa N, Yasuda H, Mochizuki S, et al. Severe osteoporosis in mice lacking osteoclastogenesis inhibitory factor/osteoprotegerin. Biochem Biophys Res Commun. 1998;247(3):610-5.

22. Bucay N, Sarosi I, Dunstan CR, Morony S, Tarpley J, Capparelli C, Scully S, Tan $\mathrm{HL}$, Xu W, Lacey DL, et al. osteoprotegerin-deficient mice develop early onset osteoporosis and arterial calcification. Genes Dev. 1998;12(9):1260-8.
23. Kong YY, Boyle WJ, Penninger JM. Osteoprotegerin ligand: a regulator of immune responses and bone physiology. Immunol Today. 2000;21(10):495502.

24. Hofbauer LC, Schoppet M. Clinical implications of the osteoprotegerin/RANKL/ RANK system for bone and vascular diseases. JAMA. 2004;292(4):490-5.

25. Klejna K, Naumnik B, Koc-Zorawska E, Mysliwiec M. Effect of unfractionated and low-molecular-weight heparin on OPG, sRANKL, and von Willebrand factor concentrations during hemodialysis. Clin Appl Thromb Hemost. 2014; 20(4):433-41.

26. Jean S, Candas B, Belzile E, Morin S, Bessette L, Dodin S, Brown JP. Algorithms can be used to identify fragility fracture cases in physicianclaims databases. Osteoporos Int. 2012;23(2):483-501.

27. Kanis JA, Oden A, McCloskey EV, Johansson H, Wahl DA, Cooper C. Epidemiology IOFWGo, quality of L: a systematic review of hip fracture incidence and probability of fracture worldwide. Osteoporos Int. 2012;23(9): 2239-56.

28. Hellgren M, Nygards EB. Long-term therapy with subcutaneous heparin during pregnancy. Gynecol Obstet Investig. 1982;13(2):76-89.

29. de Swiet M, Ward PD, Fidler J, Horsman A, Katz D, Letsky E, Peacock M, Wise $\mathrm{PH}$. Prolonged heparin therapy in pregnancy causes bone demineralization. Br J Obstet Gynaecol. 1983;90(12):1129-34.

30. Ruiz-Irastorza G, Khamashta MA, Hughes GR. Heparin and osteoporosis during pregnancy: 2002 update. Lupus. 2002;11(10):680-2.

31. Lefkou E, Khamashta M, Hampson G, Hunt BJ. Review: low-molecular-weight heparin-induced osteoporosis and osteoporotic fractures: a myth or an existing entity? Lupus. 2010;19(1):3-12.

32. Muir JM, Hirsh J, Weitz JI, Andrew M, Young E, Shaughnessy SG. A histomorphometric comparison of the effects of heparin and lowmolecular-weight heparin on cancellous bone in rats. Blood. 1997;89(9): 3236-42.

33. Wagner J, Jhaveri KD, Rosen L, Sunday S, Mathew AT, Fishbane S. Increased bone fractures among elderly United States hemodialysis patients. Nephrol Dial Transplant. 2014;29(1):146-51.

34. Vestergaard $P$, Rejnmark L, Mosekilde L. Fracture risk in patients with different types of cancer. Acta Oncol. 2009;48(1):105-15.

35. Lopez AM, Pena MA, Hernandez R, Val F, Martin B, Riancho JA. Fracture risk in patients with prostate cancer on androgen deprivation therapy. Osteoporos Int. 2005;16(6):707-11.

36. Kanis JA, McCloskey EV, Powles T, Paterson AH, Ashley S, Spector T. A high incidence of vertebral fracture in women with breast cancer. Br J Cancer. 1999;79(7-8):1179-81.

37. Brown SA, Guise TA. Cancer-associated bone disease. Curr Osteoporos Rep. 2007:5(3):120-7.

38. Coleman RE. Clinical features of metastatic bone disease and risk of skeletal morbidity. Clin Cancer Res. 2006;12(20 Pt 2):6243s-9s.

39. Maduro JH, Pras E, Willemse PH, de Vries EG. Acute and long-term toxicity following radiotherapy alone or in combination with chemotherapy for locally advanced cervical cancer. Cancer Treat Rev. 2003;29(6):471-88.

40. van Leeuwen BL, Kamps WA, Jansen HW, Hoekstra HJ. The effect of chemotherapy on the growing skeleton. Cancer Treat Rev. 2000;26(5):363-76.

41. Theriault RL. Pathophysiology and implications of cancer treatment-induced bone loss. Oncology (Williston Park). 2004;18(5 Suppl 3):11-5.

42. Yoshida A, Nakamura Y, Shimizu A, Harada M, Kameda Y, Nagano A, Inaba $M$, Asaga T. Significance of the parathyroid hormone-related protein expression in breast carcinoma. Breast Cancer. 2000;7(3):215-20.

43. Dennis MS, Lo KM, McDowall M, West T. Fractures after stroke: frequency, types, and associations. Stroke. 2002;33(3):728-34.

44. Luan L, Li R, Wang Z, Hou X, Gu W, Wang X, Yan S, Xu D. Stroke increases the risk of hip fracture: a systematic review and meta-analysis. Osteoporos Int. 2016;27(11):3149-54.

45. Huo K, Hashim SI, Yong KL, Su H, Qu QM. Impact and risk factors of poststroke bone fracture. World J Exp Med. 2016;6(1):1-8.

46. Fisher A, Srikusalanukul W, Davis M, Smith P. Poststroke hip fracture: prevalence, clinical characteristics, mineral-bone metabolism, outcomes, and gaps in prevention. Stroke Res Treat. 2013;2013:641943.

\section{Publisher's Note}

Springer Nature remains neutral with regard to jurisdictional claims in published maps and institutional affiliations. 